\title{
Evaluation of high-intensity ultrasonication for the inactivation of endospores of 3 bacillus species in nonfat milk
}

\author{
Som Nath Khanal, ${ }^{*}$ Sanjeev Anand, ${ }^{* 1}$ and Kasiviswanathan Muthukumarappan $†$ \\ *Midwest Dairy Foods Research Center, Dairy Science Department, and \\ †Department of Agricultural and Biosystems Engineering, South Dakota State University, Brookings 57007
}

\begin{abstract}
Endospores of Bacillus licheniformis [American Type Culture Collection (ATCC) 6634], Bacillus coagulans (ATCC 12245), and Geobacillus stearothermophilus (ATCC 15952) were spiked in sterile nonfat milk, and subjected to high intensity batch ultrasonication treatment at different amplitudes (80 or 100\%) and durations (1 to $10 \mathrm{~min}$ ). Increasing the amplitude from 80 to $100 \%$ did not result in enhanced inactivation of $G$. stearothermophilus endospores. However, an increase in the duration of ultrasonication from 1 to 10 min significantly increased the inactivation of endospores of all 3 species. About $48.96 \%$ of the G. stearothermophilus endospores were inactivated by ultrasonication alone, whereas ultrasonication and pasteurization combined increased the inactivation to $65.74 \%$. Inactivation of endospores could be further enhanced to $75.32 \%$ by ultrasonication and higher heat $\left(80^{\circ} \mathrm{C} / 1 \mathrm{~min}\right)$ combination. Endospores of B. licheniformis and B. coagulans were inactivated to a lesser extent compared with $G$. stearothermophilus spores. Ultrasonicated B. licheniformis endospores germinated in higher numbers when compared with untreated endospores resulting in their greater inactivation during the combined treatment. During microstructure imaging of ultrasonicated endospores, although no structural damage was noticed, they showed irregular shrinkage and wrinkles with surface coarseness. This may also have contributed to their reduced thermal resistance, in addition to sporulation. Key words: ultrasonication, sporeformers, nonfat milk, endospore
\end{abstract}

\section{INTRODUCTION}

Aerobic spore-forming bacilli are potential milkspoilage organisms. Their endospores can survive milk pasteurization, germinate, and grow in the product,

Received January 15, 2014.

Accepted June 26, 2014.

${ }^{1}$ Corresponding author: Sanjeev.anand@sdstate.edu thereby producing enzymes, acids, and other metabolites that can cause alteration in sensory properties of milk (Kalogridou-Vassiliadou, 1992; Berkeley, 2008). Most importantly, the psychrotrophic thermophiles, which can grow at refrigerated temperatures, have a much higher milk-spoilage potential than the obligate thermophiles or mesophiles (Burgess et al., 2010). Spores of these bacilli resist thermal treatment and germinate in products, whereas the vegetative cells grow further at refrigeration temperature, thereby continuing the product's spoilage. Such peculiar natures of spore-forming psychrotrophs highlight their important role in milk and dairy products spoilage (Meer et al., 1991). Shelf life is considered to be reduced when psychrotrophic counts in milk and dairy products rises to a level of $7 \log \mathrm{cfu} / \mathrm{mL}$ or $1 \mathrm{~g}$ of the product (Berkeley, 2008; Heyndrickx and Scheldeman, 2008).

The resistance of bacterial endospores to different physical and biochemical treatments, dormancy, adhesiveness, and prompt germination under favorable conditions make them important contaminants in dairy systems (Atrih and Foster, 2002). Bacillus species are frequently isolated from various heat-treated milk products, such as pasteurized milk, UHT-processed milk, milk powder, cheese, and yogurt (Faille et al., 2001). Spores are generally unaffected by a variety of chemicals, including acids, bases, oxidizing agents, alkylating agents, aldehydes, and organic solvents (Russell, 1990; Setlow, 2006); as the spores are highly heat resistant, several other nonthermal methods for spore removal or inactivation have been investigated with varying degrees of success, such as bactofugation (Torres-Anjel and Hedrick, 1971; Lewis and Deeth, 2009), microfiltration (Kosikowski and Mistry, 1990; Villamiel et al., 2009; Mukhopadhyay et al., 2011), and high-pressure processing (Heinz and Knorr, 2002; Farkas and Hoover, 2008; Considine et al., 2008). High-intensity ultrasonication was effective in inactivating Bacillus spp. vegetative cells (Khanal et al., 2014) and, to a minor extent, endospores suspended in liquid medium (Burgos et al., 1972). Ultrasonication operating between 20 and 100 $\mathrm{kHz}$, also referred to as power ultrasound, produces vibrations of the molecules in liquid medium, thereby 
generating disruptive physical effects such as cavitation (Bermúdez-Aguirre and Barbosa-Cánovas, 2011). During cavitation, temperature and pressure are assumed to increase inside the bubble up to $5,500^{\circ} \mathrm{C}$ and $50 \mathrm{MPa}$ respectively, which causes microbial inactivation (Raso et al., 1998; Villamiel et al., 2009; Bermúdez-Aguirre and Barbosa-Cánovas, 2011). It has been reported that the sporicidal effect of ultrasonication depends on static pressure, amplitude of ultrasonic waves, and treatment temperature microbial inactivation (Raso et al., 1998; Cameron et al. (2009). The present study was conducted to evaluate the application of ultrasonication and the combination of ultrasonication and pasteurization on the inactivation of some of the highly heat-resistant spores of Bacillus coagulans, Bacillus licheniformis, and Geobacillus stearothermophilus in nonfat milk.

\section{MATERIALS AND METHODS}

\section{Production of Endospores}

Three different aerobic spore-forming bacterial species, namely Bacillus coagulans, Bacillus licheniformis, and Geobacillus stearothermophilus, were used in this work. Pure cultures of these strains were purchased from American Type Culture Collection (ATCC; Manassas, VA; Table 1). The original bacterial strains were grown in brain-heart infusion (BHI; BD Difco, Franklin Lakes, NJ) broth by incubating at their respective optimum growth temperatures (Table 1) as per the supplier instructions. The cultures were pelleted out and preserved at $-80^{\circ} \mathrm{C}$ for future use in cryogenic vials (Cryobank, Copan Diagnostic Inc., Murrieta, CA) containing sterile beads and glycerol.

Endospores of different bacterial species were prepared by using methods suggested by Novak et al. (2005) and Martínez Viedma et al. (2010), with some modifications. Approximately $1 \mathrm{~mL}$ of actively growing broth culture of each of the spore-formers was spread-plated on the BHI agar plates $(150 \mathrm{~mm}$ o.d. $\times 15 \mathrm{~mm}$ high). The plates were incubated at the appropriate incubation temperatures (Table 1) for up to $10 \mathrm{~d}$. Spore staining of the culture was performed intermittently during the incubation period to monitor the extent of sporulation. When approximately $90 \%$ of sporulation was attained, spores were harvested using a similar method described by Wang et al. (2009). Approximately $10 \mathrm{~mL}$ of sterile distilled water was flooded on the plate's agar surface and soaked for 2 to $3 \mathrm{~min}$. The surface was scraped with sterile spreaders and the spore suspension was collected in $50-\mathrm{mL}$ sterile centrifuge tubes. The tubes were centrifuged at $4,500 \times g$ for $30 \mathrm{~min}$ and the supernatants were discarded. The pellets were washed 2 times by suspending in $20 \mathrm{~mL}$ of distilled water and then centrifuged at 4,500 $\times g$ for $30 \mathrm{~min}$ at $20^{\circ} \mathrm{C}$. Finally, the washed pellets were suspended in 10 to $15 \mathrm{~mL}$ of distilled water and heated at $85^{\circ} \mathrm{C}$ for $10 \mathrm{~min}$ to kill all the remaining vegetative cells and cooled. The spore suspensions containing $10^{7}$ to $10^{9}$ spores $/ \mathrm{mL}$ were stored at $-18^{\circ} \mathrm{C}$ up to $1 \mathrm{mo}$.

\section{Ultrasonication of Milk Samples}

Nonfat milk collected from the dairy plant of South Dakota State University was autoclaved at $121^{\circ} \mathrm{C}$ for $15 \mathrm{~min}$, cooled, and stored at $4^{\circ} \mathrm{C}$ before use. Spore suspensions were prepared in sterilized distilled water and inoculated in $250 \mathrm{~mL}$ of sterile cold milk at $\sim \log$ 5 to $6 \mathrm{cfu} / \mathrm{mL}$. Spore-inoculated samples $(20 \mathrm{~mL})$ in sterilized glass vials $(28 \mathrm{~mm}$ o.d. $\times 75 \mathrm{~mm}$ high) were subjected to ultrasonication treatments.

A 500-W, 20-kHz Vibra-Cell high intensity ultrasonic Processor VC 505 (Sonics \& Materials Inc., Newtown, CT) with a stainless steel-coated 13-mm titanium solid probe was used for ultrasonication of milk. The equipment had provision to adjust the pulse continuity and the amplitudes (20 to 100\%); it could be operated from $1 \mathrm{~s}$ to several hours of time. The equipment also had the ability to measure the ultrasonication power being generated during the process. The height of the probe from the bottom of the sample container was adjusted to 3 to $4 \mathrm{~cm}$ by moving the probe holder vertically. Before inserting in to the sample, the probe was washed thoroughly and disinfected by flooding with $70 \%$ ethanol. Any residual ethanol on the probe was washed off with sterile distilled water.

A 2 by 3 factorial experiment with 2 amplitudes and 3 treatment times was designed to obtain the most

Table 1. Organisms, sources, growth media, and optimum temperatures ${ }^{1}$

\begin{tabular}{lllc}
\hline Organism & Source & $\begin{array}{l}\text { Growth } \\
\text { media }\end{array}$ & $\begin{array}{c}\text { Growth } \\
\text { temperature }\left({ }^{\circ} \mathrm{C}\right)\end{array}$ \\
\hline Bacillus coagulans (ATCC 12245) & ATCC & BHI broth/agar & 37 \\
Bacillus licheniformis (ATCC 6634) & ATCC & BHI broth/agar & 30 \\
Geobacillus stearothermophilus (ATCC 15952) & ATCC & BHI broth/agar & 55 \\
\hline
\end{tabular}

${ }^{1}$ ATCC $=$ American Type Culture Collection; BHI = brain-heart infusion. 
effective ultrasonication parameters. Samples were ultrasonicated at amplitude levels of 80 and $100 \%$ (100\% corresponds to $114 \mu \mathrm{m}$ ) for time durations of 1,5 , and 10 min. Ultrasonication was carried out using a slight modification of the method as described by Cameron et al. (2009). Milk samples $(20 \mathrm{~mL})$ were ultrasonicated in $25 \mathrm{~mL}$ of borosilicate sterilized glass vials. The vials containing milk samples were immersed in an ice bath at $0^{\circ} \mathrm{C}$ to prevent any excessive temperature rise during ultrasonication. Ultrasonic waves were applied to the sample by maintaining 3 -s on-off pulses without affecting the net ultrasonication time. After completion of sonication, temperatures of the sample were recorded. Vials were sealed, cooled to $\sim 4^{\circ} \mathrm{C}$ by placing in an ice bath, and stored at the same temperature until plating. Ultrasonication amplitude was selected on the basis of maximum consistent power generated, and the percentage decline in Geobacillus stearothermophilus (ATCC 15952) spore count after ultrasonication.

Ultrasonication of milk inoculated with B. licheniformis (ATCC 6634) or B. coagulans (ATCC 12245) spores was carried out in a similar way at a selected (constant) amplitude for 1, 5, and $10 \mathrm{~min}$. Samples were stored at $\sim 4^{\circ} \mathrm{C}$ for maximum $6 \mathrm{~h}$ of ultrasonication and surviving spores counts were compared with that of corresponding untreated samples (controls).

\section{Heat Treatment of Samples}

Milk samples (treated or control) were subjected to heat treatment by similar methods. Exactly $2 \mathrm{~mL}$ of samples were transferred in sterile test tubes $(10 \times$ $75 \mathrm{~mm}$ ) and heated by immersing in a temperaturecontrolled $\left(63.5^{\circ} \mathrm{C}\right)$ water bath. The samples reached $63.5^{\circ} \mathrm{C}$ within $3 \mathrm{~min}$ and were allowed to remain at the same temperature for exactly $30 \mathrm{~min}$. After 30 min, samples were transferred to an ice water bath and cooled to 3 to $5^{\circ} \mathrm{C}$ within 10 min before plating. For the high-heat treatment purpose, only the ultrasonicated samples with G. stearothermophilus spores were heated to $80^{\circ} \mathrm{C}$ for $1 \mathrm{~min}$ and cooled down to 3 to $5^{\circ} \mathrm{C}$ before agar plating. Spore counts before and after heat treatments were obtained and compared.

\section{Germination of Ultrasonicated Endospores}

Spore suspension ( $6.5 \log \mathrm{cfu} / \mathrm{mL}$, with no live vegetative cells) of B. licheniformis (ATCC 6634) in nonfat milk was ultrasonicated at the $80 \%$ amplitude level for $10 \mathrm{~min}$. Following ultrasonication, $2 \mathrm{~mL}$ of milk (in 5 -mL sterile test tubes) was incubated at $30^{\circ} \mathrm{C}$ to allow spore germination up to $300 \mathrm{~min}$. Control samples (without ultrasonication) were also incubated parallel to the ultrasonicated samples. Control and ultrasonicated samples were taken out of the incubator at the interval of $60 \mathrm{~min}$. To kill the vegetative cells formed after spore germination, the samples were heat treated at $63^{\circ} \mathrm{C}$ for $30 \mathrm{~min}$, as described above. Survived spores were counted before and after heat treatment. As vegetative cells of same species are not resistant to the applied heat treatment (Khanal et al., 2014), any decline in numbers after heat treatment are the number of spores germinated in cells. The numbers of ultrasonicated spores that had undergone germination were compared with the untreated spores over the germination time of 0 to $300 \mathrm{~min}$.

\section{Enumeration of Endospores}

Spores were enumerated in the milk samples by the aerobic spread plate technique on Tryptone Glucose Extract Agar (BD Difco) plates. Samples were serially diluted in sterile PBS solution at $\mathrm{pH}$ 7.4. Plates were incubated for 24 to $48 \mathrm{~h}$ and 25 to 250 colonies were counted. Colony-forming units per milliliter of samples were calculated using a method suggested by Wehr and Frank (2004).

\section{Microscopic Examination of Endospores}

Spores were observed under the scanning electron microscope for any posttreatment changes by using a similar method described by Bulla et al. (1969) and Khanal et al. (2014). The spores were suspended in sterile distilled water at $\sim 5 \log \mathrm{cfu} / \mathrm{mL}$ and the suspension was ultrasonicated and pasteurized. Exactly $15 \mu \mathrm{L}$ each of the untreated, ultrasonicated, and ultrasonicated and pasteurized spore suspensions were placed on $10 \times 15 \mathrm{~mm}$ clean and sterile glass slides and air dried. Smears were sputter coated with a 5-nm layer of gold using a CRC-150 sputtering system (Plasma Science Inc., Lorton, VA). Slides were observed at different magnifications under a Hitachi scanning electron microscope (model S-3400N, Hitachi SCI Systems Ltd., Tokyo, Japan) at a beam accelerating voltage of $30 \mathrm{kV}$ and a working distance of 8.0 to $8.5 \mathrm{~mm}$.

\section{Statistical Analysis}

The trials were repeated twice with 3 replications in each experiment. Statistical analyses were carried out using SAS software, version 9.2 (SAS Institute Inc. Cary, NC). Mean values $(\mathrm{n}=6)$ were compared by $t$-test and ANOVA with least significance difference at $P<0.05$. 
Table 2. Effect of pasteurization treatment on inactivation of spores of bacilli in nonfat milk

\begin{tabular}{|c|c|c|c|}
\hline \multirow[b]{2}{*}{ Species $^{1}$} & \multicolumn{2}{|c|}{ Average count (log cfu/mL) } & \multirow[b]{2}{*}{$\begin{array}{l}\mathrm{Log} \\
\text { reduction }\end{array}$} \\
\hline & Initial & $\begin{array}{c}\text { After } \\
\text { pasteurization }\end{array}$ & \\
\hline Bacillus coagulans (ATCC 12245) & $5.51^{\mathrm{a}}$ & $5.42^{\mathrm{a}}$ & 0.09 \\
\hline Bacillus licheniformis (ATCC 6634) & $4.26^{\mathrm{b}}$ & $4.25^{\mathrm{b}}$ & 0.01 \\
\hline Geobacillus stearothermophilus (ATCC 15962) & $5.48^{\mathrm{a}}$ & $5.39^{\mathrm{a}}$ & 0.09 \\
\hline
\end{tabular}

\section{RESULTS AND DISCUSSION}

\section{Sporulation of Bacillus Species}

Adequate levels of sporulation of B. coagulans (ATCC 12245), B. licheniformis (ATCC 6634), and G. stearothermophilus (ATCC 15952) were achieved using BHI agar plates. After harvesting, endospore suspensions of up to $9.0 \log \mathrm{cfu} / \mathrm{mL}$ were obtained for B. licheniformis; whereas, in the case of $G$. stearothermophilus and $B$. coagulans, suspensions with endospore concentrations up to $7.0 \log \mathrm{cfu} / \mathrm{mL}$ could be obtained.

\section{Thermal Resistance of Bacillus Endospores}

The results on the effectiveness of pasteurization treatment on endospores of B. coagulans (ATCC 12245), B. licheniformis (ATCC 6634), and G. stearothermophilus (ATCC 15952) are shown in Table 2. No significant difference $(P>0.05)$ was noted between the log spore counts before and after pasteurization for all 3 types of endospores. Survivability of bacillus spores during pasteurization is not unusual, as these spores are not inactivated even by far more severe thermal treatments. The D-values of many of the bacillus spores at $100^{\circ} \mathrm{C}$ is more than $100 \mathrm{~min}$ in different media, including $\mathrm{pH}$ neutral Ringer solution and milk (Scheldeman et al., 2006; Dogan et al., 2009). However, the heat resistance of spores in milk and milk products may vary on the milk constituent's concentration as well as the individuality of the spore species (Behringer and Kessler, 1992).

\section{Standardization of Ultrasonication Treatment Parameters}

To select the most effective treatment, 6 treatment combinations, including 2 ultrasonication amplitude levels (100 and 80\%) and 3 time durations (1, 5, and $10 \mathrm{~min})$, were compared. Power generation during the treatment and the corresponding temperature rise were observed. Effectiveness of these treatments on the inactivation of $G$. stearothermophilus endospores in milk was also compared, and the most effective treatment combination was selected as explained herein.

Ultrasonic Power and Temperature Increase. Results of the effect of amplitude and time on ultrasonic power generation during the treatment are presented in Table 3. In 20-mL samples treated at $80 \%$ amplitude, mean power generation after 1 and 5 min was 63.45 and $63.55 \mathrm{~W}$, respectively, and was not significantly different $(P>0.05)$. A significantly higher level of ultrasonic power generation $(73.58 \mathrm{~W})$ was observed for $10 \mathrm{~min}$ of sonication time. In comparison, the power generated at $100 \%$ amplitude was $94.18,83.66$, and $72.68 \mathrm{~W}$ for 1,5 , and $10 \mathrm{~min}$ of ultrasonication time, respectively (Table 3).

Temperature increases during ultrasonication at different treatments are presented in Table 3. When 20

Table 3. Temperature increase and power generation during ultrasonication treatment of nonfat milk

\begin{tabular}{|c|c|c|c|}
\hline $\begin{array}{l}\text { Amplitude }{ }^{1} \\
(\%)\end{array}$ & $\begin{array}{l}\text { Time } \\
(\min )\end{array}$ & $\begin{array}{c}\text { Temperature increase } \\
\pm \text { SEM }\left({ }^{\circ} \mathrm{C}\right)\end{array}$ & $\begin{array}{l}\text { Ultrasonic power } \\
\text { generated } \pm \text { SEM } \\
\quad(\mathrm{W} ; \mathrm{n}=6)\end{array}$ \\
\hline \multirow[t]{3}{*}{80} & 1 & $22.7 \pm 0.31^{\mathrm{c}}$ & $63.45 \pm 0.36^{\mathrm{d}}$ \\
\hline & 5 & $28.2 \pm 0.39^{\mathrm{b}}$ & $63.55 \pm 0.55^{\mathrm{d}}$ \\
\hline & 10 & $33.7 \pm 0.46^{\mathrm{a}}$ & $73.58 \pm 0.48^{\mathrm{c}}$ \\
\hline \multirow[t]{3}{*}{100} & 1 & $29.3 \pm 0.57^{\mathrm{b}}$ & $94.18 \pm 1.11^{\mathrm{a}}$ \\
\hline & 5 & $32.7 \pm 0.51^{\mathrm{a}}$ & $83.66 \pm 1.72^{\mathrm{b}}$ \\
\hline & 10 & $33.9 \pm 0.57^{\mathrm{a}}$ & $72.68 \pm 0.60^{\mathrm{c}}$ \\
\hline
\end{tabular}

${ }^{\mathrm{a}-\mathrm{d}}$ Means within the column with different superscripts are significantly different $(P<0.05)$.

${ }^{1} 100$ and $80 \%$ of amplitude correspond to 114 and $91.2 \mu \mathrm{m}$, respectively. 
Table 4. Standardization of the ultrasonication parameters using Geobacillus stearothermophilus spores in nonfat milk ${ }^{1}$

\begin{tabular}{lcccc}
\hline $\begin{array}{l}\text { Amplitude } \\
(\%)\end{array}$ & $\begin{array}{c}\text { Time } \\
(\mathrm{min})\end{array}$ & $\begin{array}{c}\text { Average initial } \\
\text { count }(\mathrm{cfu} / \mathrm{mL})\end{array}$ & $\begin{array}{c}\text { Average final } \\
\text { count }(\mathrm{cfu} / \mathrm{mL})\end{array}$ & $\begin{array}{c}\text { Reduction of } \\
\text { spores (\%) } \pm \text { SEM } \\
(\mathrm{n}=6)\end{array}$ \\
\hline 80 & 1 & $9.29 \times 10^{5}$ & $7.95 \times 10^{5}$ & $14.46 \pm 4.25^{\mathrm{c}}$ \\
& 5 & $7.77 \times 10^{5}$ & $6.47 \times 10^{5}$ & $16.70 \pm 3.49^{\mathrm{c}}$ \\
100 & 10 & $8.96 \times 10^{5}$ & $4.57 \times 10^{5}$ & $48.96 \pm 3.17^{\mathrm{a}}$ \\
& 1 & $8.70 \times 10^{5}$ & $7.66 \times 10^{5}$ & $11.96 \pm 4.79^{\mathrm{c}}$ \\
& 5 & $8.45 \times 10^{5}$ & $6.65 \times 10^{5}$ & $21.26 \pm 4.69^{\mathrm{bc}}$ \\
& 10 & $8.09 \times 10^{5}$ & $5.50 \times 10^{5}$ & $32.01 \pm 4.16^{\mathrm{b}}$ \\
\hline
\end{tabular}

${ }^{\mathrm{a}-\mathrm{c}}$ Means within a column with different superscripts are significantly different $(P<0.05)$.

$\mathrm{mL}$ of sample was ultrasonicated at the $80 \%$ amplitude level, the average increase in temperature during 1 , 5 , and 10 min was $22.71,28.16$, and $33.71^{\circ} \mathrm{C}$, respectively. At $100 \%$ amplitude, the temperature increased by $29.35,32.66$, and $33.91^{\circ} \mathrm{C}$, respectively, for the 3 treatment times. Values of power generated and temperature increase obtained by varying amplitude and treatment time were analyzed by 2-way ANOVA. It was observed that the effect of amplitude, time, and interaction of amplitude and time on power generation was significant $(P<0.0001)$. Similarly, a significant effect $(P<0.0001)$ was observed for amplitude, time, and interaction of amplitude and time in temperature increase.

The results of the experiments revealed that 63 to $73.58 \mathrm{~W}$ of power was generated at $80 \%$ amplitude and 10 min ultrasonication time. In addition, the power generated was more consistent during the extended ultrasonication time of 10 min. At $100 \%$ amplitude a higher value of power was generated (72.68 to 94.18 W), but unlike at $80 \%$ amplitude, power dropped during longer ultrasonication time of $10 \mathrm{~min}$. Sonication at $80 \%$ amplitude did not cause any churning, as the ultrasonic waves were apparently absorbed in to the sample itself. Conversely, sonication at 100\% amplitude produced rigorous agitation of milk. As similar ultrasonication treatments produced markedly lesser power generation in the air medium, it may be assumed that the excessive churning and splashing might have reduced the contact surface between sonotrode and milk medium, thereby causing the reduced power generation.

Effectiveness of Amplitude and Ultrasonication Time on Endospore Inactivation. Geobacillus stearothermophilus endospores were chosen as the test organism because its spores are considered the most heat resistant and are used in testing sterility of the autoclaving process (Rutala et al., 1982). A nonfat milk sample spiked with spores was ultrasonicated at 80 and $100 \%$ amplitude levels for 1, 5, and $10 \mathrm{~min}$. The effect of ultrasonication amplitude and time on G. stearothermophilus is shown in Table 4. The mean percent reductions in spore counts in samples treated at $80 \%$ amplitude for 1,5 , and 10 min were 14.46 , 16.67 , and $48.96 \%$, respectively. When similar samples were ultrasonicated at $100 \%$ amplitude for 1,5 , and 10 min, $11.96,21.26$, and $32.01 \%$ of spore inactivation was achieved, respectively (Table 4).

The increased amplitude from 80 to $100 \%$ did not have a significant $(P=0.1524)$ effect on the inactivation of $G$. stearothermophilus spores. Conversely, increasing ultrasonication time from 1 to 10 min significantly increased $(P<0.0001)$ spore inactivation. The interaction effect of amplitude and time was significant $(P<0.0426)$; however, the main effect of amplitude was not significant. This means that the increase in amplitude from 80 to $100 \%$ did not result in a significant increase in spore inactivation. A comparison of means of percent spore reductions corresponding to the individual treatments with least significant difference (Table 4) showed the $80 \%$ amplitude level for $10 \mathrm{~min}$ resulted in the highest inactivation of spores. Based on the analysis of temperature rise, power generation, and spore inactivation, $80 \%$ amplitude was selected as optimum to be used in further studies. Even though 10 min of sonication time resulted in maximum inactivation, treatment times of 1,5 , and 10 min were tested in other spores, assuming that different spores may have differences in resistance to ultrasonication.

The effectiveness of ultrasonication on liquid medium depends on different factors, including frequency, power, amplitude, and treatment time. In addition, pressure, temperature, viscosity, and concentration of solids also affect the overall ultrasonication effectiveness in many ways (Mason et al., 1996; Patist and Bates, 2008). The intensity of ultrasonication was reported to be proportional to the amplitude of vibration of the sonotrode, and, in general, the increase in amplitude was also found to increase the overall effectiveness of ultrasonication (Santos et al., 2009; Kentish and Ashokkumar, 2011). Conversely, a minimum intensity is required to achieve the cavitation threshold for a particular liquid medium while passing ultrasonication waves in it. The amplitudes higher than the threshold may not always produce favorable results during extraction or inactiva- 
tion processes. Moreover, higher amplitude may also cause a rapid fall of the ultrasonic transducer that may result in vigorous liquid agitation, thereby causing poor cavitation (Santos et al., 2009). Temperature of the medium is another important factor that governs the effectiveness of ultrasonication. More intense ultrasonic cavitation can be attained at lower temperatures when other ultrasonic parameters are constant (Santos et al., 2009). Piyasena et al. (2003) described the temperature to be an extremely important factor that affects ultrasonication effectiveness. Temperature is reported to be inversely related to the cavitation threshold. At higher temperatures, the vapor pressure of the solvent rises and the vapor fills the cavitation bubbles, thereby causing them to collapse less violently. This leads to the overall decrease in cavitation and the effect produced is lesser than expected (Santos et al., 2009). One way to extend the effect of cavitation is to increase the ultrasonication time. Extended ultrasonication time from 1 to $10 \mathrm{~min}$ at constant amplitude was found to be effective in inactivating additional 3 logs of Anoxybacillus flavithermus cells in skim milk, as reported in our previous study (Khanal et al., 2014). Intense cavitation can also be produced by ultrasonication of increased volume of the sample, but this may not always support the inactivation of cells or spores possibly because the net ultrasonication energy per unit volume may not change (Joyce et al., 2003a,b).

\section{Effectiveness of Ultrasonication Treatment on Bacterial Endospores}

Durations of 1,5 , and 10 min of ultrasonication inactivated $0.52,14.9$, and $33.2 \%$ of B. licheniformis spores, respectively. A combined effect of ultrasonication and pasteurization resulted in $13.1,29.5$, and $37.9 \%$ of spore inactivation for all 3 treatment times, respectively (Table 5). For B. coagulans, ultrasonication alone for 1,5 , and 10 min resulted in $12.95,11.63$, and $35.63 \%$ of spore reduction. When ultrasonicated spores were subjected to pasteurization, the inactivation levels increased to $24.55,28.07$, and $50.39 \%$, respectively (Table $5)$. The inactivation levels achieved in the case of $G$. stearothermophilus endospores were 14.46, 16.90, and $48.96 \%$ when subjected to ultrasonication alone for 1 , 5 , and $10 \mathrm{~min}$; whereas, ultrasonication and pasteurization combined resulted in increased levels of 18.90, 21.47 , and $65.74 \%$ of spore inactivation. Ultrasonication for $10 \mathrm{~min}$ and heating at a higher temperature of $80^{\circ} \mathrm{C}$ for $1 \mathrm{~min}$ further increased inactivation of $G$. stearothermophilus endospores to $75.3 \%$ (Table 5). In comparison to ultrasonication alone, significant increases $(P<0.05)$ were observed for inactivation of all 3 spore types when ultrasonicated samples were pasteurized (Table 5, Figure 1). The results obtained in the present study showed that when treatment time increased to $10 \mathrm{~min}$, percent reduction in $B$. coagulans and G. stearothermophilus endospores significantly increased to 35.63 and $48.96 \%$, respectively (Figure 1). The overall effect of ultrasonication time was observed to be significant for inactivation of all tested spores.

Previous reports indicate that longer ultrasonication times are required to achieve inactivation of spores beyond $1 \mathrm{log}$. Short treatment times, up to $12 \mathrm{~min}$, did not cause the spore inactivation as such, but reduced their resistance to thermal treatments (Burgos et al., 1972). Betts and) Williams (1999) have reported heating in combination with ultrasonication as one of the most commonly applied inactivation techniques. They have reported a greater inactivation of bacteria and

Table 5. Effect of ultrasonication and ultrasonication plus pasteurization on bacilli spores in nonfat milk

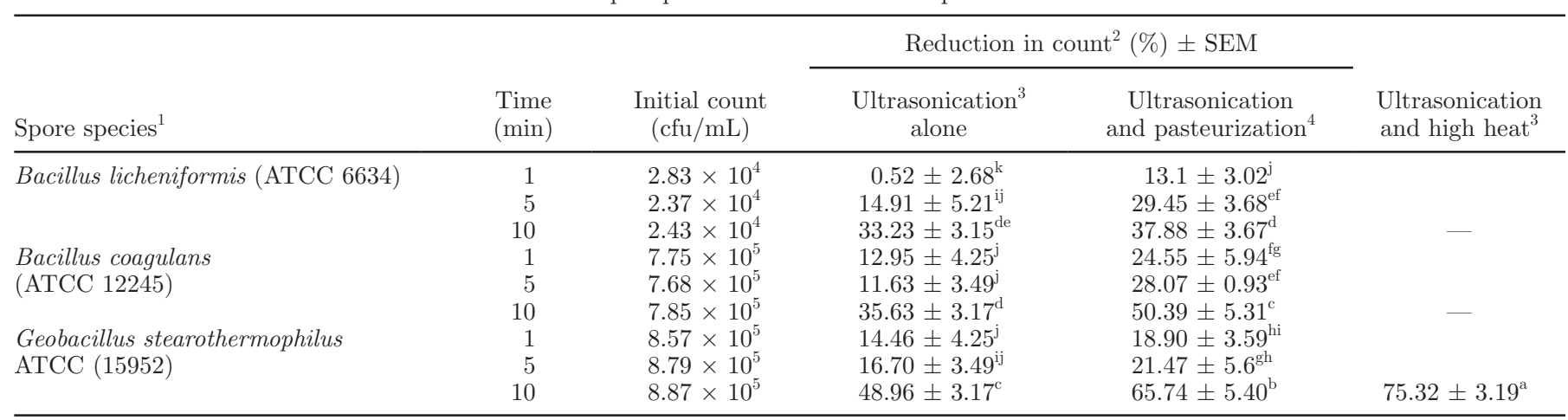

\footnotetext{
${ }^{1} \mathrm{ATCC}=$ American Type Culture Collection.

${ }^{2} 80^{\circ} \mathrm{C}$ for $1 \mathrm{~min}$.

${ }^{3}$ Ultrasonication at $80 \%$ amplitude.

${ }^{4}$ Pasteurization at $63^{\circ} \mathrm{C}$ for $30 \mathrm{~min}$.
}

${ }^{\mathrm{a}-\mathrm{k}}$ Means with different superscripts are significantly different $(P<0.05)$. 


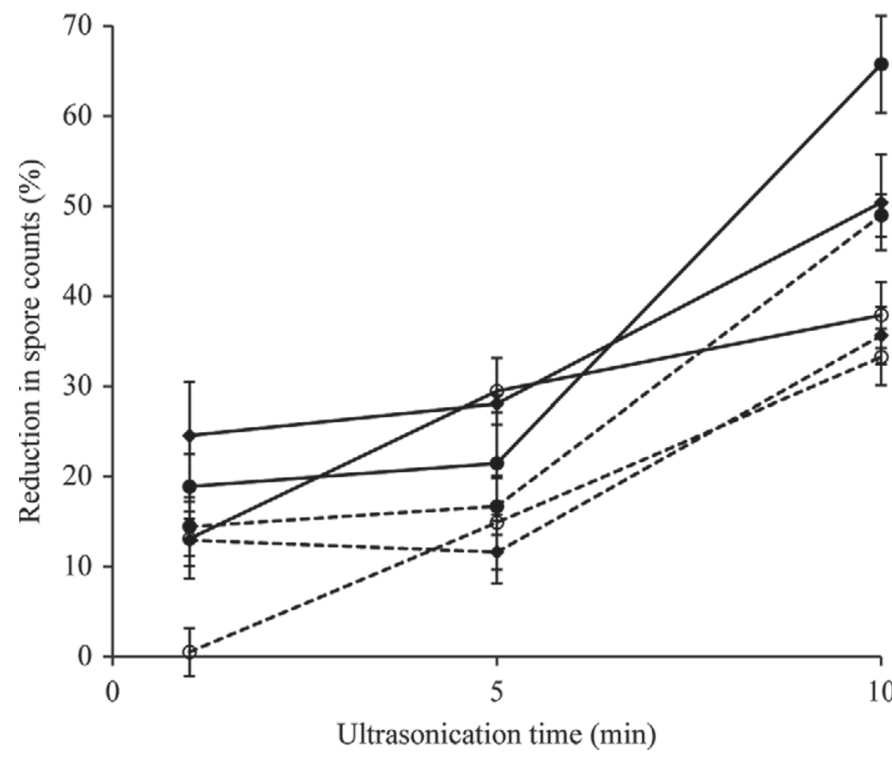

Figure 1. Effect of ultrasonication and ultrasonication plus pasteurization on inactivation of bacilli spores in nonfat milk. An open circle $(\bigcirc)$ represents Bacillus licheniformis [American Type Culture Collection (ATCC) 6634] spores; a diamond ( ) represents Bacillus coagulans (ATCC 12245); and a filled circle (•) represents Geobacillus stearothermophilus (ATCC 15952) spores. Dotted lines (...) represent ultrasonication at $80 \%$ amplitude $(91.2 \mu \mathrm{m})$ for $10 \mathrm{~min}$. Solid lines $(-)$ represent ultrasonication at $80 \%$ amplitude $(91.2 \mu \mathrm{m})$ for $10 \mathrm{~min}$ followed by pasteurization at $63^{\circ} \mathrm{C}$ for $30 \mathrm{~min}$. $(\mathrm{n}=6$; error bar denotes SEM).

spores by heat when preceded by ultrasonication. In another report, ultrasonication resulted in a decrease of the thermal resistance of bacterial spores up to $43 \%$ (Betts and Williams, 1999). Similarly, a decline in Dvalue of ultrasonication-treated $B$. licheniformis spores in ringer solution has also been reported by Burgos et al. (1972). Those authors also reported that the $\mathrm{D}$-value of Bacillus cereus spores at $110^{\circ} \mathrm{C}$ decreased from 11.5 to approximately $1.5 \mathrm{~min}$ as a result of ultrasonication treatment. Ultrasonication in combination with thermal treatment (thermosonication) led to more than $99.9 \%$ of B. subtilis spore inactivation (Raso et al., 1998). The overall results from the present study indicate reduction in thermal resistance of bacterial endospores already subjected to ultrasonication in skim milk. This effect is more likely due to the germination of endospores, as evident by the results obtained during the study conducted with $B$. licheniformis endospores.

\section{Effect of Ultrasonication on Endospore Germination in Nonfat Milk}

We hypothesized that the ultrasonication would induce endospore germination, which was verified by allowing the ultrasonicated endospores to germinate (by incubation). These germinated endospores (in the form of vegetative cells) were more susceptible to heat treatments, such as pasteurization, compared with nonultrasonicated endospores. The survival counts for $B$. licheniformis endospores subjected to germination (with or without ultrasonication) followed by heat treatment are presented in Table 6 . The results revealed that a greater number of endospores germinated in the ultrasonicated samples as compared with the untreated samples. Heat treatment $\left(63^{\circ} \mathrm{C}\right.$ for $\left.30 \mathrm{~min}\right)$ alone did not result in any reduction in endospore counts in nonultrasonicated sample. Conversely, mean counts of $6.02 \log \mathrm{cfu} / \mathrm{mL}$ were reduced by $0.48 \operatorname{logs}$ when ultrasonicated ( $80 \%$ amplitude for 10 min) milk samples were subjected to heat treatment. Endospore survival continued to decrease gradually as the ultrasonicated samples were incubated for germination before the heat treatment (Table 6, Figure 2).

After $300 \mathrm{~min}$ of incubation the endospore counts were $5.35 \log \mathrm{cfu} / \mathrm{mL}$ in treated samples, as compared with the nonultrasonicated samples that showed a higher endospore survival of $5.85 \log \mathrm{cfu} / \mathrm{mL}$. Thus, the results indirectly indicated a greater reduction of endospores by $\sim 0.50 \log \mathrm{cfu} / \mathrm{mL}$ due to complete or partial germination of the ultrasonicated endospores during incubation. Overall, $68 \%$ or more ultrasonicated endospores were heat inactivated in comparison to the nonultrasonicated endospores. The difference in thermally resistant endospore counts between ultrasonicated and nonultrasonicated samples was consistent

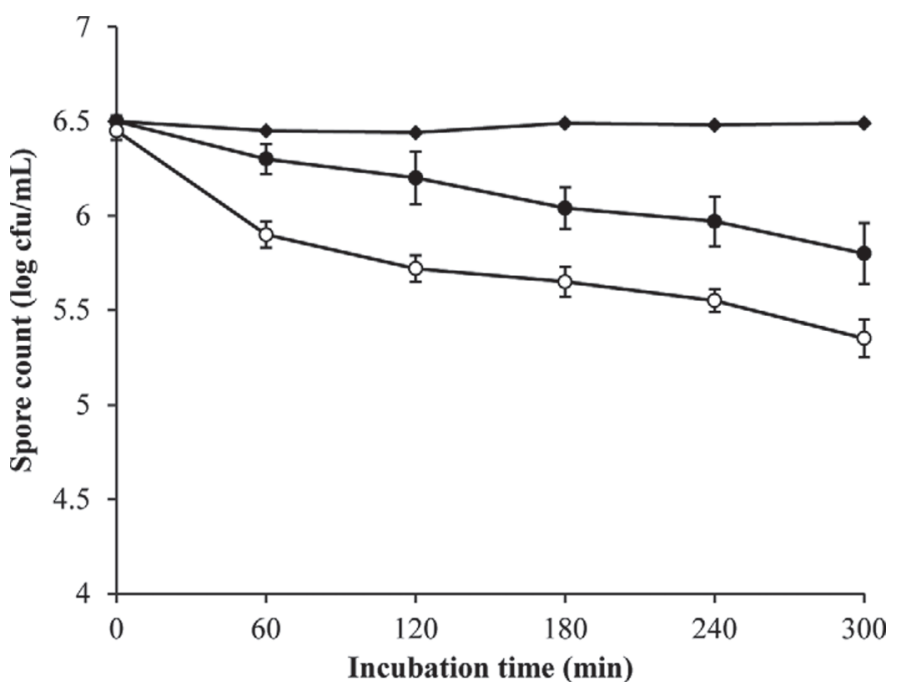

Figure 2. Effect of ultrasonication on germination of Bacillus licheniformis (American Type Culture Collection 6634) spores in nonfat milk at $30^{\circ} \mathrm{C}$. A diamond $(\checkmark)$ indicates the spore count without any treatment; a closed circle $(\bullet)$ indicates spore count after pasteurization at $63^{\circ} \mathrm{C}$ for $30 \mathrm{~min}$; and an open circle $(\bigcirc)$ represents spores ultrasonicated at $80 \%$ amplitude $(91.2 \mu \mathrm{m})$ for $10 \mathrm{~min}$ and heat treated at $63^{\circ} \mathrm{C}$ for 30 min. $(\mathrm{n}=6$; error bar denotes $\mathrm{SEM})$. 
Table 6. Effect of ultrasonication on germination of Bacillus licheniformis spores in nonfat milk

\begin{tabular}{|c|c|c|c|c|}
\hline \multirow[b]{2}{*}{$\begin{array}{l}\text { Incubation }^{1} \\
\text { time (min) }\end{array}$} & \multicolumn{3}{|c|}{ Count (log cfu/mL \pm SEM) } & \multirow[b]{2}{*}{$\Delta \log ^{4}$} \\
\hline & $\begin{array}{c}\text { Incubated without } \\
\text { treatment }\end{array}$ & $\begin{array}{c}\text { Incubated without } \\
\text { treatment and } \\
\text { pasteurized }\end{array}$ & $\begin{array}{c}\text { Ultrasonicated }^{2} \\
\text { incubated and } \\
\text { pasteurized }^{3}\end{array}$ & \\
\hline 0 & $6.50 \pm 0.03^{\mathrm{a}}$ & $6.50 \pm 0.03^{\mathrm{a}}$ & $6.45 \pm 0.48^{\mathrm{a}}$ & 0.48 \\
\hline 60 & $6.45 \pm 0.01^{\mathrm{a}}$ & $6.30 \pm 0.08^{\mathrm{a}}$ & $5.90 \pm 0.60^{\mathrm{bc}}$ & 0.60 \\
\hline 120 & $6.44 \pm 0.01^{\mathrm{a}}$ & $6.20 \pm 0.14^{\mathrm{ab}}$ & $5.72 \pm 0.78^{\mathrm{cd}}$ & 0.78 \\
\hline 180 & $6.49 \pm 0.01^{\mathrm{a}}$ & $6.04 \pm 0.11^{\mathrm{bc}}$ & $5.65 \pm 0.85^{\mathrm{de}}$ & 0.85 \\
\hline 240 & $6.48 \pm 0.01^{\mathrm{a}}$ & $5.97 \pm 0.13^{\mathrm{bc}}$ & $5.55 \pm 0.95^{\mathrm{de}}$ & 0.95 \\
\hline 300 & $6.49 \pm 0.02^{\mathrm{a}}$ & $5.80 \pm 0.16^{\mathrm{bc}}$ & $5.35 \pm 1.15^{\mathrm{e}}$ & 1.15 \\
\hline
\end{tabular}

${ }^{\mathrm{a} e}$ Means with different superscripts are significantly different $(P<0.05)$.

${ }^{1}$ Incubated at $30^{\circ} \mathrm{C}$.

${ }^{2}$ Ultrasonicated at $80 \%$ amplitude for $10 \mathrm{~min}$.

${ }^{3} \mathrm{At} 63^{\circ} \mathrm{C}$ for $30 \mathrm{~min}$.

${ }^{4}$ Difference between Log counts of untreated spores after heat treatment and ultrasonicated spore after heat treatment.

during the germination time from 60 to $300 \mathrm{~min}$ (Figure 2). When spores, suspended in milk, are incubated, some spores start germinating into vegetative cells. As their vegetative counterparts (cells) are not thermally resistant, they can be inactivated after the pasteurization treatment that results in a reduced survival count.
In cases of ultrasonicated samples, a relatively higher number of spores might have germinated, resulting in a higher percentage reduction in spore counts in comparison to the control (untreated sample). It is obvious that all the spores do not germinate at once, the extended incubation time allowed a higher number of spores
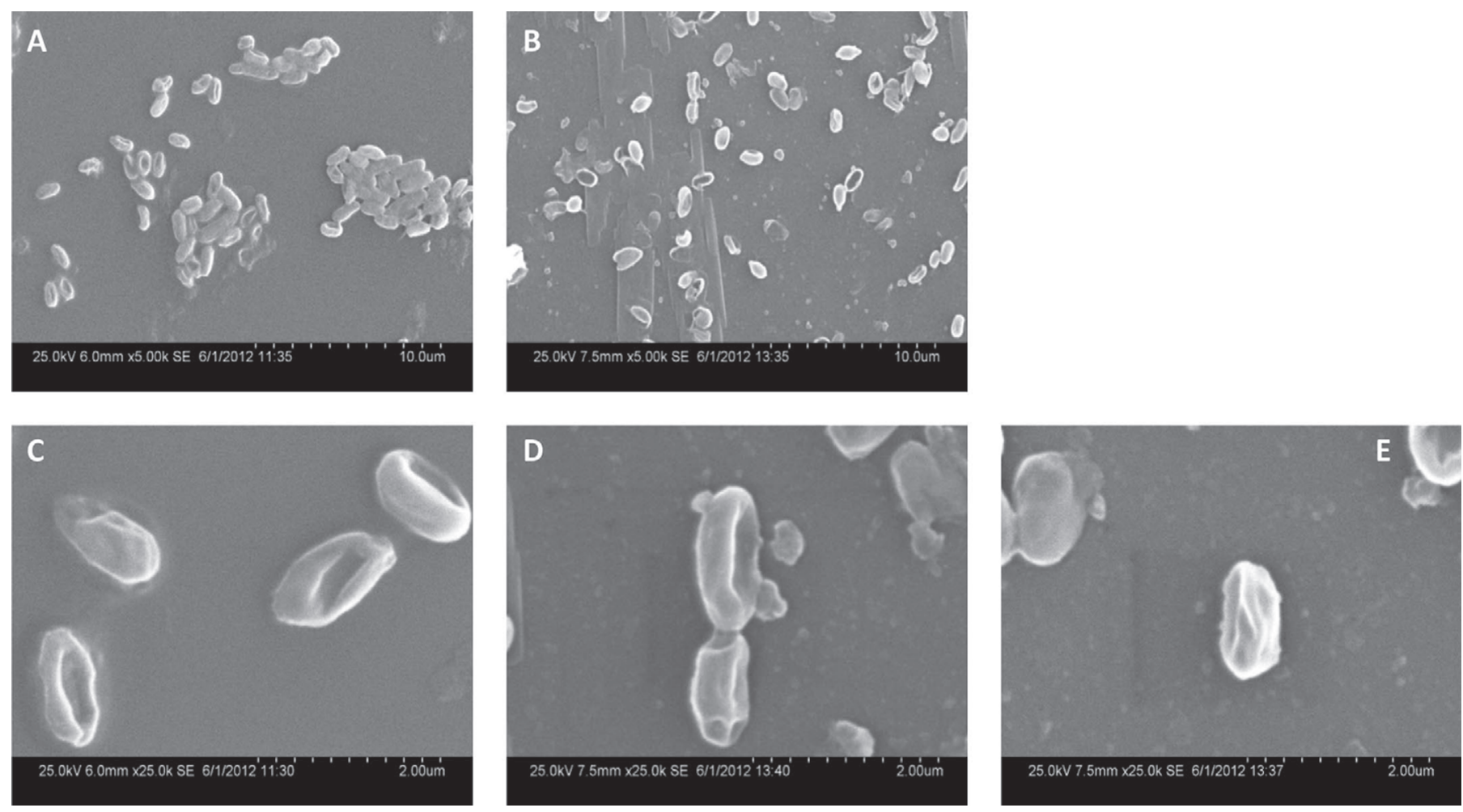

Figure 3. Scanning electron microscopic images of Bacillus licheniformis (American Type Culture Collection 6634) spores. (A) Before ultrasonication, viewed at lower magnification $(5,000 \times)$. (B) After ultrasonication at $91.2 \mu \mathrm{m}$ amplitude for 10 min, viewed at lower magnification $(5,000 \times)$. (C) Before ultrasonication, viewed at higher magnification $(25,000 \times)$. (D) After ultrasonication at $91.2 \mu \mathrm{m}$, viewed at higher magnification $(25,000 \times)$. (E) After ultrasonication at $91.2 \mu \mathrm{m}$ and pasteurization $\left(63^{\circ} \mathrm{C}, 30 \mathrm{~min}\right)$, viewed at higher magnification $(25,000 \times)$. 

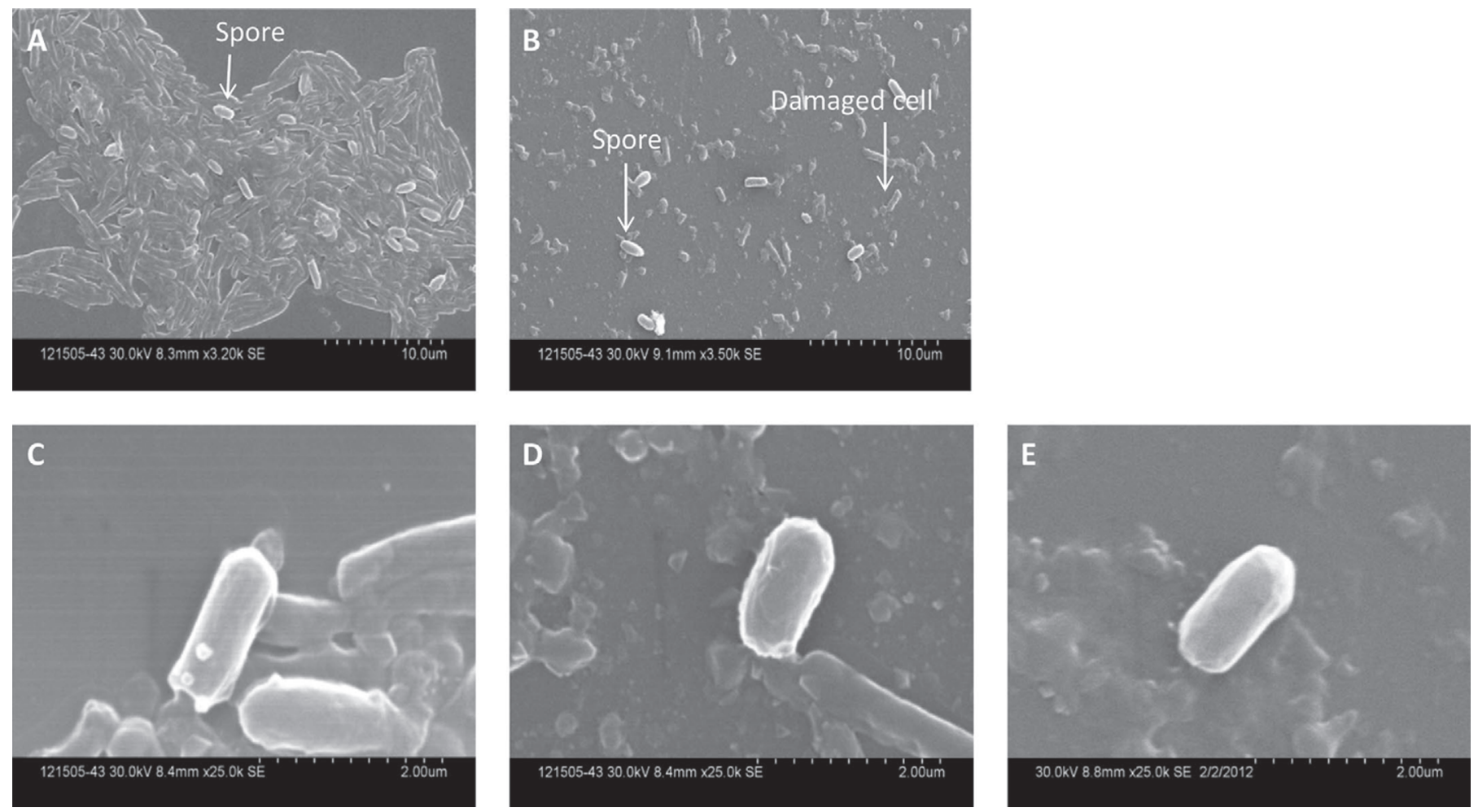

Figure 4. Scanning electron microscopic images of Bacillus coagulans (American Type Culture Collection 12245) spores. (A) Before ultrasonication, viewed at lower magnification $(3,200 \times)$. (B) After ultrasonication at $91.2 \mu \mathrm{m}$ amplitude for 10 min, viewed at lower magnification $(3,500 \times)$. (C) Before ultrasonication, viewed at higher magnification $(25,000 \times)$. (D) After ultrasonication at $91.2 \mu \mathrm{m}$, viewed at higher magnification $(25,000 \times)$. (E) After ultrasonication at $91.2 \mu \mathrm{m}$ and pasteurization $\left(63^{\circ} \mathrm{C}, 30 \mathrm{~min}\right)$, viewed at higher magnification $(25,000 \times)$.

to germinate, leading to higher reductions in counts after heating. Information on effectiveness of ultrasonication in induction of spore germination is scarcely available; however, some reports have suggested that spores exposed to a sublethal dose of any treatment may germinate faster. Atrih and Foster (2002) reported activation of spore germination by thermal treatment that was insufficient to kill them. They also observed extraction of some of the coat proteins by a sublethal $\mathrm{NaOH}$ treatment that eventually speeded up germination. Germination of spores in presence of nutritional medium was also reported to be induced by a prior sublethal heat treatment termed as heat induction (Setlow, 2003; Wei et al., 2010). Induction of spore germination by a treatment insufficient to kill the spore has also been described in the case of high-pressure processing of cheese (López-Pedemonte et al., 2003). Spore germination is essentially a degradative biophysical process, which commences with increase in fluidity of the spore's inner membrane and initiation of ion fluxes, thereby allowing movement of monovalent cations (potassium and sodium) across the spore membrane (Setlow, 2003). The increased induction of endospore germination by ultrasonication can be explained on the basis of the assumption that the $\mathrm{Ca}^{2+}$-DPA (dipicolinic acid) released from any 1 endospore, due to any reason, may excite the neighboring endospores to germinate (Setlow, 2003).

\section{Effect of Ultrasonication on Morphology of Endospores}

Endospores of B. coagulans, G. stearothermophilus, and $B$. licheniformis were visualized under the scanning electron microscope. The images of endospores after ultrasonication at $80 \%$ amplitude for $10 \mathrm{~min}$, as well as a combined ultrasonication and pasteurization treatment $\left(63^{\circ} \mathrm{C}\right.$ for $\left.30 \mathrm{~min}\right)$, were taken at different magnifications for comparison purposes. The images were observed for physical damages such as cracks, fissures, or leakage of core materials.

The endospores of $B$. licheniformis before and after subjecting to ultrasonication and combined ultrasonication-pasteurization treatments are shown in Figure 3. These spores were 1.2 to $1.5 \mu \mathrm{m}$ in length and 0.72 to $0.82 \mu \mathrm{m}$ in width (data not shown). In the images taken at a lower magnification of 3,000 to $5,000 \times$, the vegetative cells and spores were clearly distinguished. 
The spores were observed as shorter, denser, and rice grain-like structures; whereas, vegetative cells were rod shaped and closely gelled together. After ultrasonication, spores structures were almost similar to the untreated spores; whereas, the vegetative cells were disintegrated in to pieces (Figure 3). The images of $B$. coagulans endospores at $25,000 \times$ magnification gave a more clear view on morphology. The spore surface before ultrasonication was smooth and shiny, which turned into a rough or coarse surface after ultrasonication. The spore structure remained unchanged upon thermal treatment of the ultrasonicated spores (Figure 4).

A similar effect of ultrasonication was observed on the endospores of G. stearothermophilus (Figure 5). The shape and surface smoothness of the $G$. stearothermophilus spores was almost similar to the $B$. coagulans endospores. Conversely, B. licheniformis endospore surface was observed as irregular, with shrinkages, wrinkles, and ridges (Figure 4). Similar to B. coagulans, no changes were observed in G. stearothermophilus and $B$. licheniformis endospores' morphology after ultrasonication or combined ultrasonication and pasteurization treatment. The spore surfaces of all the observed species were clean and free of matrices, indicating that ultrasonication cleaned the adhering materials surrounding the endospores.

Bradley and Williams (1957) studied different types of Bacillus spores, including B. licheniformis, under transmission electron microscope, and reported structures similar to the ones obtained in our study. Their transmission electron microscope images of $B$. licheniformis spores, obtained as carbon replica, also showed irregular shrinkages and wrinkles in the spore surface. Laroussi (2002) used scanning electron microscopy to obtain images of $B$. subtilis spores followed by exposure to nonthermal atmospheric plasma and observed the damaged surfaces of spores subjected to the treatments. Lerouge et al. (2001) also used scanning electron microscopy to evaluate the effect of nonthermal plasma discharge on unknown Bacillus spp. spores and reported some distinct differences in spore surfaces after the treatment. Chandler et al. (2001) found the spore surface to be smooth and regular before treatments, whereas ultrasonicated spores showed evidence of breakages, surface damage, and emergence of pustules on the surface due to leakage of spore contents through the broken layers. We did not observe any evidence of major structural changes in the spores in
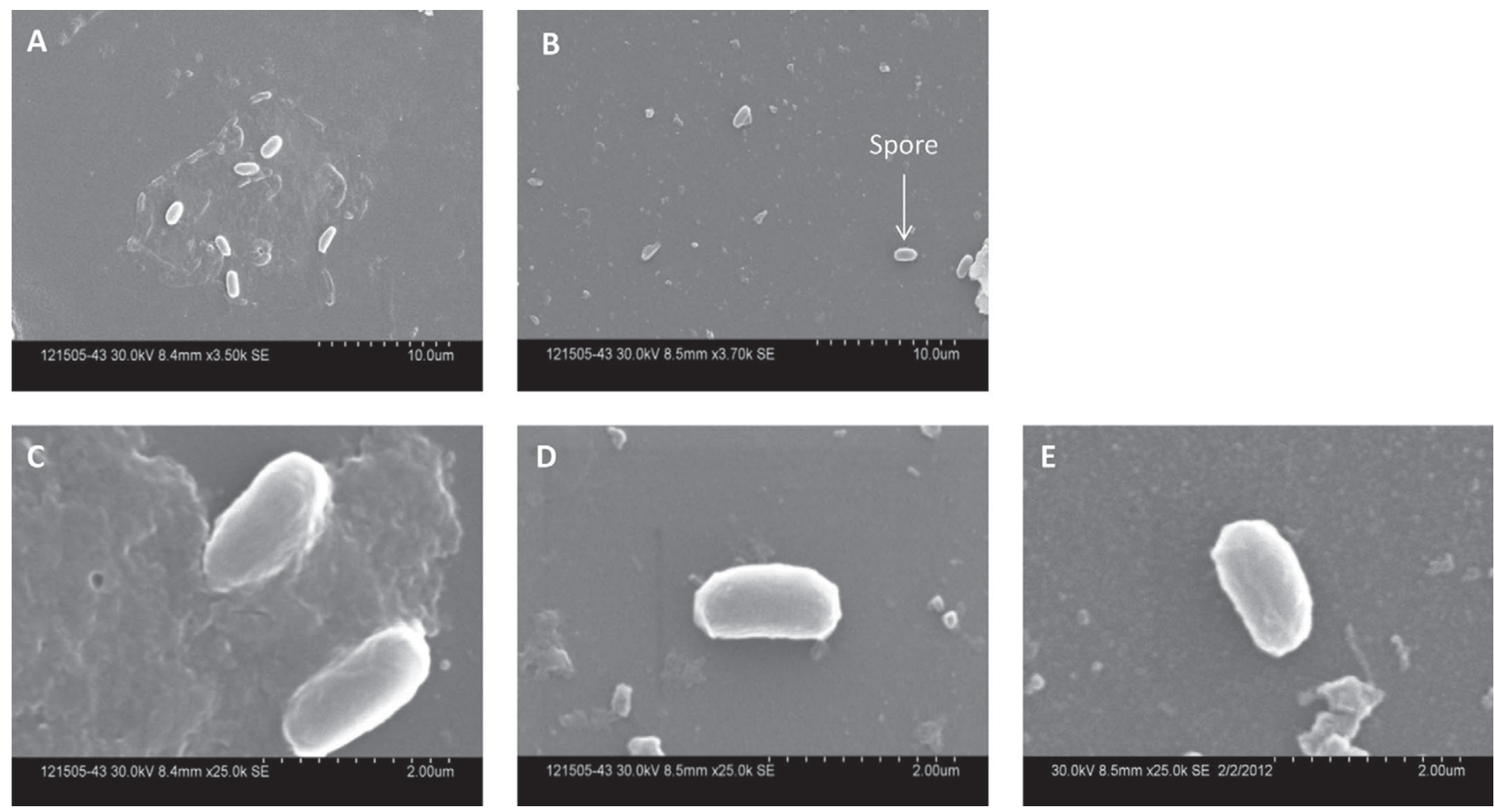

Figure 5. Scanning electron microscopic images of Geobacillus stearothermophilus (American Type Culture Collection 15952) spores. (A) Before ultrasonication, viewed at lower magnification $(3,200 \times)$. (B) After ultrasonication at $91.2 \mu \mathrm{m}$ amplitude for 10 min, viewed at lower magnification $(3,500 \times)$. (C) Before ultrasonication, viewed at higher magnification $(25,000 \times)$. (D) After ultrasonication at $91.2 \mu$ m, viewed at higher magnification $(25,000 \times)$. (E) After ultrasonication at $91.2 \mu \mathrm{m}$ and pasteurization $\left(63^{\circ} \mathrm{C}, 30 \mathrm{~min}\right)$, viewed at higher magnification $(25,000 \times)$. 
this research. Lesser damage to the spore's surfaces by ultrasonication was probably due to their robust spore coat, relatively oval-shaped structure, and minimal size. In comparison to the long rod-shaped vegetative counterparts, oval-shaped smaller spores might have lesser inertia to sustain such damage. Moreover, the spore membranes are expected to be relatively brittle at lower temperatures, and the violent shaking during ultrasonication in our research might have ruptured the inner membranes of the spore. Such internal damages might have caused leakage of the materials from the core making them unable to germinate.

\section{CONCLUSIONS}

Combination of ultrasonication and pasteurization resulted in an overall endospore inactivation up to $65.74 \%$. When ultrasonication was followed by a higher heat treatment $\left(80^{\circ} \mathrm{C}\right.$ for $\left.1 \mathrm{~min}\right)$, the endospore inactivation was further enhanced. This shows that ultrasonication reduced the resistance of endospores to thermal treatment such as pasteurization. Increased ultrasonication amplitude did not result in any increase in the endospore inactivation levels. It was the increase in ultrasonication time that had a significant influence on the endospore inactivation. Ultrasonication induced a greater number of spores to germinate, resulting in a higher reduction in endospore counts after pasteurization. Microscopic observation did not reveal any severe damage to the structure of endospores at these levels of treatment. The results from our study thus provide preliminary evidence on the possible application of ultrasonication and pasteurization combined for the inactivation of bacterial endospores in skim milk. The findings of our study may be useful in further research in scaled-up capacities so as to understand the effectiveness of high-throughput continuous flow ultrasonication as an aid to spore inactivation along with continuous pasteurization of milk.

\section{ACKNOWLEDGMENTS}

This work was funded by Dairy Management Inc. and administered by the Dairy Research Institute (Rosemont, IL). S. M. Khanal acknowledges the Fulbright scholarship grant for his MS assistantship. The authors also acknowledge the support of the Agricultural Experiment Station, South Dakota State University, in conducting the study.

\section{REFERENCES}

Atrih, A., and S. J. Foster. 2002. Bacterial endospores the ultimate survivors. Int. Dairy J. 12:217-223.
Behringer, R., and H. G. Kessler. 1992. Influence of individual milk constituents on the heat resistance of Bacillus licheniformis and Bacillus stearothermophilus spores. Int. Dairy J. 2:243-255.

Berkeley, R. C. W. 2008. Whither Bacillus? Pages 1-7 in Applications and Systematics of Bacillus and Relatives. R. Berkeley, M. Heyndrickx, N. Logan, and P. Vos, ed. Wiley-Blackwell, Hoboken, NJ.

Bermúdez-Aguirre, D., and G. V. Barbosa-Cánovas. 2011. Power ultrasound to process dairy products. Pages 445-465 in Ultrasound Technologies for Food and Bioprocessing. H. Feng, G. BarbosaCanovas, and J. Weiss, ed. Springer, New York, NY.

Betts, G., and A. Williams. 1999. Ultrasonic standing waves: Inactivation of food-borne microorganisms using power ultrasound. In Encyclopedia of Food Microbiology. Academic Press, Waltham, MA.

Bradley, D. E., and D. J. Williams. 1957. An electron microscope study of the spores of some species of the genus Bacillus using carbon replicas. J. Gen. Microbiol. 17:75-79.

Bulla, L. A., G. S. Julian, R. A. Rhodes, and C. W. Hesseltine. 1969. Scanning electron and phase-contrast microscopy of bacterial spores. Appl. Microbiol. 18:490-495.

Burgess, S. A., D. Lindsay, and S. H. Flint. 2010. Thermophilic bacilli and their importance in dairy processing. Int. J. Food Microbiol. $144: 215-225$.

Burgos, J., J. A. Ordonez, and F. Sala. 1972. Effect of ultrasonic waves on the heat resistance of Bacillus cereus and Bacillus licheniformis spores. Appl. Microbiol. 24:497-498.

Cameron, M., L. McMaster, and T. Britz. 2009. Impact of ultrasound on dairy spoilage microbes and milk components. Dairy Sci. Technol. 89:83-98.

Chandler, D. P., J. Brown, C. J. Bruckner-Lea, L. Olson, G. J. Posakony, J. R. Stults, and L. J. Bond. 2001. Continuous spore disruption using radially focused, high-frequency ultrasound. Anal. Chem. 73:3784-3789

Considine, K. M., A. L. Kelly, G. F. Fitzgerald, C. Hill, and R. D. Sleator. 2008. High-pressure processing-Effects on microbial food safety and food quality. FEMS Microbiol. Lett. 281:1-9.

Dogan, Z., K. Weidendorfer, M. Müller-Merbach, F. Lembke, and J. Hinrichs. 2009. Inactivation kinetics of Bacillus spores in batchand continuous-heating systems . LWT Food Sci. Technol. (Campinas.) $42: 81-86$

Faille, C., F. Fontaine, and T. Bénézech. 2001. Potential occurrence of adhering living Bacillus spores in milk product processing lines. J. Appl. Microbiol. 90:892-900.

Farkas, D. F., and D. G. Hoover. 2008. High pressure processing. J. Food Sci. 65(Suppl. 8):47-64.

Heinz, V., and D. Knorr. 2002. Effects of high pressure on spores. Pages 77-113 in Ultra High Pressure Treatments of Foods. M. G. Hendrickx, D. Knorr, L. Ludikhuyze, A. Loey, and V. Heinz, ed. Springer, New York, NY.

Heyndrickx, M., and P. Scheldeman. 2008. Bacilli associated with spoilage in dairy products and other foods. Pages 64-82 in Applications and Systematics of Bacillus and Relatives. R. Berkeley, M. Heyndrickx, N. Logan, and P. Vos, ed. Wiley-Blackwell, Hoboken, NJ.

Joyce, E., T. J. Mason, S. S. Phull, and J. P. Lorimer. 2003a. The development and evaluation of electrolysis in conjunction with power ultrasound for the disinfection of bacterial suspensions. Ultrason. Sonochem. 10:231-234.

Joyce, E., S. S. Phull, J. P. Lorimer, and T. J. Mason. 2003b. The development and evaluation of ultrasound for the treatment of bacterial suspensions. A study of frequency, power and sonication time on cultured Bacillus species. Ultrason. Sonochem. 10:315-318.

Kalogridou-Vassiliadou, D. 1992. Biochemical activities of Bacillus species isolated from flat sour evaporated milk. J. Dairy Sci. 75:2681-2686

Kentish, S., and M. Ashokkumar. 2011. The physical and chemical effects of ultrasound. Pages 1-12 in Ultrasound Technologies for Food and Bioprocessing. H. Feng, G. Barbosa-Canovas, and J. Weiss, ed. Springer, New York, NY.

Khanal, S. N., S. Anand, K. Muthukumarappan, and M. Huegli. 2014. Inactivation of thermoduric aerobic sporeformers in milk by ultrasonication. Food Contr. 37:232-239. 
Kosikowski, F., and V. Mistry. 1990. Microfiltration, ultrafiltration, and centrifugation separation and sterilization processes for improving milk and cheese quality. J. Dairy Sci. 73:1411-1419.

Laroussi, M. 2002. Nonthermal decontamination of biological media by atmospheric-pressure plasmas: Review, analysis, and prospects. Plasma Sci. 30:1409-1415.

Lerouge, S., M. R. Wertheimer, and L. H. Yahia. 2001. Plasma sterilization: A review of parameters, mechanisms, and limitations. Plasmas Polym. 6:175-188.

Lewis, M. J., and H. C. Deeth. 2009. Heat treatment of milk. Pages 168-204 in Milk Processing and Quality Management. A. Tamime, ed. Wiley-Blackwell, Hoboken, NJ.

López-Pedemonte, T. J., A. X. Roig-Sagués, A. J. Trujillo, M. Capellas, and B. Guamis. 2003. Inactivation of spores of Bacillus cereus in cheese by high hydrostatic pressure with the addition of nisin or lysozyme. J. Dairy Sci. 86:3075-3081.

Martínez Viedma, P., H. Abriouel, N. Ben Omar, R. Lucas López, and A. Gálvez. 2010. Effect of enterocin EJ97 against Geobacillus stearothermophilus vegetative cells and endospores in canned foods and beverages. Eur. Food Res. Technol. 230:513-519.

Mason, T. J., L. Paniwnyk, and J. P. Lorimer. 1996. The uses of ultrasound in food technology. Ultrason. Sonochem. 3:S253-S260.

Meer, R. R., J. Baker, F. W. Bodyfelt, and M. W. Griffiths. 1991. Psychotrophic Bacillus spp. in fluid milk products: A review. J. Food Prot. 54:969-979.

Mukhopadhyay, S., P. M. Tomasula, J. B. Luchansky, A. Porto-Fett, and J. E. Call. 2011. Removal of Bacillus anthracis spore from commercial unpasteurized liquid egg white using cross-flow microfiltration. J. Food Process. Preserv. 35:550-562.

Novak, J. S., J. Call, P. Tomasula, and J. B. Luchansky. 2005. An assessment of pasteurization treatment of water, media, and milk with respect to Bacillus spores. J. Food Prot. 68:751-757.

Patist, A., and D. Bates. 2008. Ultrasonic innovations in the food industry: From the laboratory to commercial production. Innov. Food Sci. Emerg. Technol. 9:147-154.

Piyasena, P., E. Mohareb, and R. C. McKellar. 2003. Inactivation of microbes using ultrasound: A review. J. Food Microl. 87:207-216.
Raso, J., A. Palop, R. Pagán, and S. Condón. 1998. Inactivation of Bacillus subtilis spores by combining ultrasonic waves under pressure and mild heat treatment. J. Appl. Microbiol. 85:849-854.

Russell, A. D. 1990. Bacterial spores and chemical sporicidal agents. Clin. Microbiol. Rev. 3:99-119.

Rutala, W. A., M. M. Stiegel, and F. A. Sarubbi. 1982. Decontamination of laboratory microbiological waste by steam sterilization. Appl. Environ. Microbiol. 43:1311-1316.

Santos, H. M., C. Lodeiro, and J.-L. Capelo-Martínez. 2009. The power of ultrasound. Pages 1-16 in Ultrasound in ChemistryAnalytical Applications. J. Capelo-Martínez, ed. Wiley-Blackwell, Hoboken, NJ.

Scheldeman, P., L. Herman, S. Foster, and M. Heyndrickx. 2006. Bacillus sporothermodurans and other highly heat-resistant spore formers in milk. J. Appl. Microbiol. 101:542-555.

Setlow, P. 2003. Spore germination. Curr. Opin. Microbiol. 6:550-556.

Setlow, P. 2006. Spores of Bacillus subtilis: Their resistance to and killing by radiation, heat and chemicals. J. Appl. Microbiol. 101:514-525

Torres-Anjel, M. J., and T. I. Hedrick. 1971. Spore removal by centrifugation and its effect on ultra-high temperature commercial sterilization of milk. J. Dairy Sci. 54:326-330.

Villamiel, M., M. A. I. Schutyser, and P. De Jong. 2009. Novel methods of milk processing. Pages 205-236 in Milk Processing and Quality Management. A. Tamime, ed. Wiley-Blackwell, Hoboken, NJ.

Wang, B.-S., B.-S. Li, Q.-X. Zeng, J. Huang, Z. Ruan, Z.-W. Zhu, and L. I. N. Li. 2009. Inactivation kinetics and reduction of Bacillus coagulans spore by the combination of high pressure and moderate heat. J. Food Process Eng. 32:692-708.

Wehr, H. M., and J. F. Frank. 2004. Standard Methods for the Examination of Dairy Products. 17th ed. American Public Health Association, Washington, DC.

Wei, J., I. M. Shah, S. Ghosh, J. Dworkin, D. G. Hoover, and P. Setlow. 2010. Superdormant spores of Bacillus species germinate normally with high pressure, peptidoglycan fragments and bryostatin. J. Bacteriol. 192:1455-1458. 